REVISTA DE GESTÃO ESECRETARIADO

MANAGEMENT AND ADMINISTRATIVE

PROFESSIONAL REVIEW

ISSN: 2178-9010
Revista GeSec

São Paulo, SP, Brasil

v. 12 , n. 2, p. $173-202$

maio /ago. 2021

DOI: http://dx.doi.org/10.7769/gesec.v12i2.1188

\title{
Implantação da gestão por competência em uma instituição de ensino superior pública: desafios e perspectivas
}

\section{Implementation of competence management in a public higher education institution: challenges and perspectives}

\author{
Priscila Araujo Silva ${ }^{1}$ \\ Sueli Maria de Araújo Cavalcante ${ }^{2}$ \\ Patricia Araujo Silva ${ }^{3}$ \\ Mara Rosalia Ribeiro Silva ${ }^{4}$
}

\section{Resumo}

O objetivo desta pesquisa é compreender os desafios e as perspectivas no processo de implantação da gestão por competências em uma IES. Metodologicamente, a pesquisa caracteriza-se como qualitativa, conduzida por meio de pesquisa de campo e entrevistas semiestruturadas. A pesquisa foi realizada em uma IES brasileira, tendo como sujeitos entrevistados seis servidores técnico-administrativos, os quais ocupam cargos de gestão e que participam da equipe de implantação da gestão por competências na organização. A análise dos resultados foi feita por meio de análise de conteúdo. Como principais resultados, identificou-se que, apesar da legislação obrigar à adoção da gestão por competências desde 2006, a instituição ainda não conseguiu atendê-la em decorrência do ambiente complexo; da necessidade de mudança na cultura organizacional referentes aos costumes políticos; da rigidez em sua estrutura; da necessidade de motivar servidores a se capacitarem, apesar da estabilidade da função adquirida por meio da legislação vigente, ainda não se obteve sucesso em sua efetiva implantação. Quanto às perspectivas acerca da implantação da gestão por competências, identificou-se como principais perspectivas: a regulamentação de maneiras mais objetivas de

\footnotetext{
${ }^{1}$ Mestranda em Administração na Universidade Estadual do Ceará (UECE).

${ }^{2}$ Doutora em Educação, Docente do Mestrado Profissional em Políticas Públicas e Gestão da Educação Superior na Universidade Federal do Ceará (UFC).

${ }^{3}$ Mestre em Administração, Administradora na UFC.

${ }^{4}$ Doutoranda em Administração na Universidade Federal do Paraná (UFPR).
} 
seleção de pessoas, levando-se em consideração as competências necessárias para o provimento do cargo vago; o mapeamento dos das competências de forma a alocar os servidores de acordo com as com as competências necessárias para o cargo, e não apenas para atender apenas às demandas burocrática; e a disseminação da gestão por competências como uma prioridade na cultura organizacional.

Palavras-Chave: Competência. Gestão por Competência. Setor Público.

\begin{abstract}
The objective of this research is to understand the challenges and perspectives in the process of implementing competency management in an HEI. Methodologically, the research is characterized as qualitative, conducted through field research and semi-structured interviews. The research was carried out in a Brazilian HEI, with six interviews with technicaladministrative employees, who occupy management positions and participate in the management implementation team by competencies in the organization. The analysis of the results was made through content analysis. As main results, it was identified that, despite the legislation obliging the adoption of management by competences since 2006 , the institution still has not managed to attend it due to the complex environment; the need for change in organizational culture regarding political customs; the rigidity in its structure; the need to motivate civil servants to be trained, despite the stability of the function acquired through current legislation, its effective implementation has not yet been successful. As for the perspectives on the implementation of management by competencies, the main perspectives were identified: the regulation of more objective ways of selecting people, taking into account the competencies necessary to fill the vacant position; the mapping of the competencies in order to allocate the employees according to those with the necessary competencies for the position, and not just to meet only bureaucratic demands; and the dissemination of management by competences as a priority in the organizational culture.
\end{abstract}

Keywords: Competence. Competency Management. Public Sector.

\title{
Introdução
}

No âmbito acadêmico e profissional, o tema gestão por competências está se consolidando frente às alterações percebidas no universo do trabalho e suscitando reflexões em estudiosos e profissionais do mercado, dentre outros interessados (Montezano, Medeiros, Isidro-filho \& Petry, 2019a). A gestão por competências, busca "alinhar esforços para que competências 
humanas possam gerar e sustentar competências organizacionais necessárias à consecução de objetivos estratégicos" (Pires et al., 2005, p. 19).

Esse modelo de gestão foi trazido às organizações do setor público brasileiro, mais especificamente no âmbito federal, por meio do Decreto n. 5.707 (2006), onde foi instituída a Política e as Diretrizes para o Desenvolvimento de Pessoal da administração pública federal direta, autárquica e fundacional, em busca de melhoria na gestão dessas organizações, de proporcionar o desenvolvimento permanente do servidor público, bem como de adequar as competências requeridas aos servidores e aos objetivos institucionais (Carvalho et al., 2009).

Cabe esclarecer que, em 2019, o Decreto n. 5.707 (2006) foi revogado e, em seu lugar, foi regulamentado o Decreto n. 9.991 (2019) que dispõe sobre a Política Nacional de Desenvolvimento de Pessoal (PNDP) e objetiva realizar a promoção do desenvolvimento dos servidores públicos nas competências necessárias à consecução da excelência na atuação dos órgãos e das entidades da administração pública federal direta, autárquica e fundacional. Destaca-se que o Decreto supracitado deve agir em conjunto com o Decreto n. 5.824 (2006) e Decreto n. 5.825 (2006), ainda vigentes, sendo que o primeiro estabelece os procedimentos para a concessão do incentivo à qualificação e para a efetivação do enquadramento por nível de capacitação dos servidores técnico-administrativos em educação, já o segundo estabelece os critérios para elaboração do plano de desenvolvimento dos integrantes do plano de carreira dos técnico-administrativos em educação.

Ocorre que a aplicação da gestão por competências no contexto do serviço público brasileiro tem sido considerada relativamente complexa (Dutra, Fleury, \& Ruas, 2008; Paes, de Souza Figueiredo, de Lemos \& Oliveira, 2019; Sousa \& Barbosa, 2018). Além disso, ressaltase que há instituições públicas federais ainda em estágio inicial do processo de implantação desse modelo de gestão, pois têm introduzido a gestão por competências muitos anos após a promulgação do decreto que a regula (Brantes, 2012; Rocha, Passador, \& Shinyashiki, 2017; Sousa \& Barbosa, 2018).

Nasce, assim, a necessidade de engajamento em pesquisas que busquem compreender o cenário da implantação da gestão por competências organizações públicas brasileiras, mapeando e analisando os desafios encontrados pelos servidores, bem como identificando as perspectivas referentes a esses desafios, ou seja, as prospecções de possíveis resoluções e melhorias frente às dificuldades enfrentadas. Diante do exposto, este estudo buscará resposta para a seguinte questão de pesquisa: quais os desafios e as perspectivas no processo de implantação de gestão por competências em uma IES? Este questionamento foi fonte do estabelecimento do objetivo desta pesquisa, que é compreender os desafios e as perspectivas no 
processo de implantação da gestão por competências em uma IES brasileira.

O esforço desta pesquisa justifica-se por se identificar o gap na literatura sobre o pouco conhecimento acerca da implementação, desafios e perspectivas da gestão por competências em universidades federais (Dias, Demo, Paula \& Costa, 2020; Paes et al., 2019; Rocha et al., 2017; Sousa \& Barbosa, 2018), as quais representam importantes organizações na sociedade brasileira, principalmente por conta do seu papel social universal, que é de educar pessoas e proporcionar habilidades e conhecimentos para que as futuras gerações tenham recursos suficientes para lidar com problemas globais, como a pobreza, as guerras e as mudanças climáticas (United Nations Educational, Scientific and Cultural Organization [UNESCO], 2009). Nesse contexto, o aparato administrativo e o modelo de gestão de pessoas das universidades brasileiras devem estar alinhados aos objetivos estratégicos e educacionais dessas organizações, tornando-se pertinentes às oportunidades de maior conhecimento sobre a gestão por competências das universidades federais no Brasil.

Deste modo, espera-se que o este trabalho contribua para o aprimoramento das atuais demandas requeridas ao serviço público federal no que se refere à implantação da gestão por competências, visto que há uma legislação que regula e demanda essa prática nas organizações públicas federais e cujos resultados influenciam diretamente na qualidade e eficácia dos serviços ao bem-estar dos cidadãos (Decreto n. 5.707, 2006).

Além desta introdução, o trabalho revisa, na segunda parte, a literatura sobre competências, gestão por competências e suas implicações no setor público brasileiro. A metodologia é apresentada na terceira parte e os resultados compõem a quarta parte. Discussão e síntese de resultados compõem quinta parte. As considerações finais são apresentadas na sexta e última parte do trabalho.

\section{Referencial Teórico}

\subsection{Gestão por Competências}

A raiz etimológica da palavra "competência" vem do latim "competentia", e no francês antigo significava "apropriado" (Dadoy, 2004). No contexto dos estudos organizacionais, o significado de "competência" pode ser dividido entre: competências organizacionais e individuais (Dutra, 2004). Assim, quanto às competências organizacionais, elas se caracterizam por estarem no campo estratégico das organizações, possibilitando o processo de aprendizagem organizacional e, por conseguinte, a inovação (Dutra, 2004). As competências individuais, por 
sua vez, referem-se às questões pertinentes às pessoas e como o seu conjunto de competências são aproveitadas (ou não) pelas organizações.

$\mathrm{Na}$ perspectiva individual, competência representa o conjunto interdependente das três seguintes dimensões: "conhecimentos" (o saber), "habilidades" (o saber fazer) e "atitudes" (o saber ser ou agir) necessários ao indivíduo para o cumprimento de determinado propósito (Durand, 1998). Competências são, ainda, "as características de personalidade transformadas em comportamento, que geram um desempenho de sucesso em um posto de trabalho" (Alles, 2006, p. 20). Além disso, Leme (2006) ainda propõe dividir as competências individuais em competências técnicas; estas são formadas pelos componentes de "conhecimento" (o saber) e "habilidade" (o saber fazer); e pelas competências comportamentais; formadas pelo componente "atitude" (o saber ser ou agir).

A competência, assim, não é um estado momentâneo do indivíduo ou um conhecimento específico, mas é a sua inteligência prática voltada para a solução de problemas, quando o indivíduo assume iniciativas, compreende e domina situações em constante mutação, estando ciente da natureza contingencial do mundo moderno e do seu próprio contexto de trabalho (Zarifian, 2001). Portanto, a competência refere-se ao indivíduo saber agir diante das situações do seu contexto profissional, integrando conhecimentos, recursos e habilidades, na busca pela solução de problemas (Le Boterf, 2003).

Tomando como base o entendimento de que as competências individuais representam as características de personalidade que formam o conjunto de conhecimentos, habilidades e atitudes apresentados no exercício das funções profissionais do indivíduo (Alles, 2006; Durand, 1998; Le Boterf, 2003), faz-se necessário aplicar esse conceito na dinâmica organizacional, sendo essa aplicação chamada de gestão por competências.

Para Leme (2005), a Gestão por Competências é uma ferramenta organizacional que busca levantar as necessidades dos trabalhadores, e oferecer os meios e treinamentos necessários ao seu desenvolvimento, no intuito de auxiliar a organização no alcance dos seus objetivos estratégicos. Sob o mesmo prisma, a gestão por competências, propõe-se a "alinhar esforços para que competências humanas possam gerar e sustentar competências organizacionais necessárias à consecução de objetivos estratégicos" (Pires et al., 2005, p. 19).

Por sua vez, Gramigna (2007, p. 43), define a gestão por competências como um “conjunto de ferramentas, instrumentos e processos metodológicos voltados para a gestão estratégica de pessoas". Assim, a gestão por competências está alinhada à estratégia organizacional, a qual orienta as ações da gestão no intuito de captar e desenvolver as competências necessárias para o alcance de seus objetivos organizacionais (Brandão \& 
Guimarães, 2001).

Dentre as contribuições da utilização de um sistema de gestão por competências nas organizações, este estilo de gestão agrega valor ao indivíduo, sendo que este valor não se reflete apenas no componente individual (numa dimensão mais profissional) ou coletivo, mas também ultrapassando benefícios que se irradiam para a comunidade na qual o indivíduo se posiciona, o que trará para ele o ganho social (Sansur, 2007). Para a autora, o ganho social é compreendido com um conjunto de aspectos que favorecem o desenvolvimento do trabalhador em sua dimensão mais ampliada: como pessoa, profissional, cidadão (política e socialmente determinado). Ademais, a gestão por competência pode reduzir a complexidade do ambiente e aumentar a capacitação individual e organizacional ao agrupar as competências centrais que determinam a atuação eficaz do indivíduo (Paiva \& Melo, 2008).

A literatura apresenta diferentes modelos de gestão por competências aplicadas ao contexto organizacional (Carmo, 2016; Dias, 2020). Este artigo tomará como base o modelo de Leme (2005), o qual delimita cinco etapas referentes ao processo de implantação da gestão por competências nas organizações, a saber: (i) sensibilização; (ii) mapeamento e definição do perfil de competências; (iii) identificação das competências dos colaboradores; (iv) plano de desenvolvimento e seleção; (v) mensuração avaliação e acompanhamento.

A etapa de "sensibilização" é quando os trabalhadores e a direção são orientados e conscientizados sobre a Gestão por Competências (Leme, 2005). Complementa-se que as organizações buscam sensibilizar os atores organizacionais no intuito de desenvolver o comprometimento e a motivação das equipes de trabalho (Gramigna, 2007).

Nesse contexto, a organização busca adaptar-se às mudanças organizacionais, sejam elas estruturais ou referentes ao campo estratégico, como cultura organizacional, missão e valores. Silva e Mello (2013) destacam que o grande desafio consiste em realizar a mudança de um modelo burocrático para um modelo gerencial de resultados, onde se faz necessária a alteração da cultura organizacional do serviço público, sendo necessário o comprometimento e ação dos envolvidos, bem como o alinhamento do mesmo à estratégia da instituição.

Em seguida, há a etapa de "mapeamento e definição do perfil de competências", na qual as organizações identificam as competências necessárias para o pleno desenvolvimento organizacional e o alcance de resultados de sucesso, de acordo com a sua estratégia organizacional previamente formulada (Leme, 2005). Alinhada à essa etapa, há a "identificação das competências dos colaboradores", que está relacionada ao levantamento das competências que os colaboradores apresentam, ou seja, aquelas já desenvolvidas, bem como as que a necessitam ser aprimoradas (Leme, 2005).

Revista Gestão e Secretariado (GeSec), São Paulo, SP, 12(2), maio/ago., 2021, 173-202. 
A necessidade de identificar as competências dos servidores é relevante, pois é dela que decorrem as ações de captação e desenvolvimento de competências, avaliação e retribuição (Bastos, Borges, de Mello Neto, Sainz \& de Mello, 2018, Brandão \& Bahry, 2005). Brantes (2012) ressalta que, se realizado de forma inadequada, todo o processo de implantação da gestão por competência da organização ficará prejudicado.

Sovienski e Stigar (2008) ressaltam que nem sempre uma pessoa, por mais dedicada que se mostre, é a mais qualificada a desenvolver certas atividades, tornando problemático o alcance do trabalho de forma mais produtiva. Destaca-se que todo cargo dentro das organizações deve ser preenchido pela pessoa que mais tenha as características exigidas por seu ocupante, por meio de comparação entre suas competências e as exigências do cargo em questão (Ferreira \& Soeira, 2013).

A quarta etapa refere-se ao "plano de desenvolvimento e seleção", realizada após a identificação das competências e carências dos trabalhadores já terem sido levantadas (Leme, 2005). Esta etapa busca desenvolver e treinar as competências exigidas que os trabalhadores ainda não apresentam (Leme, 2005). O treinamento é considerado como um fator crítico de sucesso para a organização e, para isso acontecer, é necessário formular e coordenar a execução de um plano de capacitação anual voltado para o desenvolvimento dos trabalhadores (Sovienski \& Stigar, 2008). Ademais, no que tange à seleção por competências, ressalta-se que este é um dos métodos mais eficazes na contratação dos trabalhadores, no sentido de ser possível identificar os candidatos com as características comportamentais adequadas para cada cargo ou função, que são as competências comportamentais (Leme, 2005).

Por fim, há a etapa de "mensuração avaliação e acompanhamento", momento em que é possível acompanhar o desenvolvimento dos colaboradores, por meio de métodos avaliativos (Leme, 2005). O processo de avaliação busca alcançar os seguintes objetivos: identificação dos pontos fortes e fracos do trabalhador; a avaliação das necessidades de formação educacional; a definição dos planos de desenvolvimento e motivação; identificação de possíveis meios de recompensas pelo trabalho prestado; e promoção de feedback da carreira do trabalhador (Milliman, Nason, Zhu, \& De Cieri, 2002). Clausen, Jones e Rich (2008) complementam que os sistemas de avaliação que se mostram mais eficazes são aqueles que indicam com precisão as responsabilidades e as contribuições dos trabalhadores, gerando efeitos de motivação e aquisição de relevantes para as tomadas de decisão pessoais dos trabalhadores.

A gestão por competências tem sido amplamente disseminada no âmbito das organizações públicas brasileiras, assunto que será dissertado a seguir. 


\subsection{Gestão por competências no setor público brasileiro}

No Brasil, a gestão por competências se tornou referencial para a gestão de pessoas desde a publicação do Decreto n. 5.707 (2006) que estabeleceu a Política Nacional de Desenvolvimento de Pessoal (PNDP), tendo as seguintes finalidades: "I) melhoria da eficiência, eficácia e qualidade dos serviços públicos prestados ao cidadão; II) desenvolvimento permanente do servidor público; III) adequação das competências requeridas dos servidores aos objetivos das instituições, tendo como referência o plano plurianual; IV) divulgação e gerenciamento das ações de capacitação; e V) racionalização e efetividade dos gastos com capacitação" (Decreto n. 5.707, 2006). Posteriormente, este Decreto foi revogado e, em seu lugar, foi promulgado o Decreto n. 9.991 (2019), também dispõe sobre a Política Nacional de Desenvolvimento de Pessoas (PNDP) da administração pública federal direta, autárquica e fundacional do Governo Federal.

A gestão por competências no setor público representa a forma como a administração pública planeja, capta, desenvolve e avalia as competências necessárias nos âmbitos individual, grupal e organizacional, a fim de alcançar os objetivos organizacionais (Brandão \& Guimarães, 2001). O modelo de gestão por competências contribui para o desenvolvimento da gestão de pessoas no setor público, uma vez que é responsável por orientar diferentes ações, como: treinamento dos servidores, avaliação do seu desempenho, gerenciamento das informações e medição de competências aliadas aos objetivos organizacionais (Campion et al., 2011).

Nesse sentido, Siqueira e Nascimento (2016) identificaram que a implementação da gestão por competências fortaleceu o conceito de equipe, estimulando a integração entre a chefia e os outros servidores. Além disso, buscou-se também criar um ambiente favorável à inovação nos processos de trabalho e, com isso, desenvolver profissionais capacitados para entregar mais serviços de melhor qualidade para a sociedade.

Ressalta-se, no entanto, que a adoção do modelo de gestão por competências ainda é recente e complexa no âmbito público, considerando que há uma variedade de ocupações de trabalho, o que implica em diferentes enunciados de competências e, consequentemente, diferentes necessidades educacionais, o que acaba requerendo autonomia e flexibilidade dos gestores destas organizações (Silva \& Mello, 2013). Fonseca e Menezes (2016), por exemplo, concluíram que a gestão por competências se encontra em um estágio pré-institucional nas organizações investigadas (agências reguladoras federais), identificando poucos casos de sucesso, alta influência do arranjo político organizacional e coexistência de dispositivos 
burocráticos e gerenciais (resultando na necessidade de uma legislação de pessoal mais consistente e integrada).

Além disso, estudos têm demonstrado diferentes entraves enfrentados por organizações públicas brasileiras na implantação da gestão por competências (Dias et al., 2020. Um importante desafio a ser superado pelas organizações públicas, é a introdução de um novo modelo de gestão voltado ao alinhamento dos objetivos individuais aos organizacionais, ao desenvolvimento e a capacitação contínua e, sobretudo, voltado ao desempenho, em contraponto com a manutenção de uma cultura organizacional divergente, dando destaque ao direito de estabilidade dos servidores públicos (Giudice, 2012).

Sousa e Barbosa (2018) revelaram que o sistema de gestão de pessoas, baseado em competências, possui uma lacuna entre o que é dito na literatura e o que é realizado na prática da organização analisada. Acredita-se que a gestão por competências é viável na administração pública brasileira, mas depende de ajustes necessários às especificidades do setor público, como a existência de uma forte estrutura legalista e a cultura burocrática do serviço público.

A pesquisa de Kriiger et al., (2018) identificou como principais entraves para a implantação de gestão por competências, a descontinuidade administrativa na gestão da organização e a necessidade sensibilização de todo o quadro de pessoal, de forma a tornar o processo de gestão por competências uma construção coletiva. Montezano, Medeiros, Pinheiro e de Oliveira (2019b), por sua vez, identificaram uma categoria nova de dificuldades relacionada aos processos inadequados de comunicação de implantação da gestão por competências. Acredita-se que a comunicação adequada poderá, dentre outros benefícios, contribuir para minimizar resistências dos servidores.

Como demais dificuldades, Cavalcante e Renault (2018) concluíram que a organização analisada possui um modelo de gestão por competências estabelecido, mas que necessita de ajustes em sua estruturação e execução. Os processos de recrutamento e seleção de servidores são baseados em conhecimentos técnicos e acadêmicos (avaliados por meio de provas objetivas) em detrimento das demais dimensões das competências (habilidades e atitudes). Em complemento, Paes, de Souza Figueiredo, de Lemos e Oliveira (2019) identificaram que na alocação dos secretários executivos predominam as competências técnicas em detrimento das competências gerenciais atribuídas ao perfil daqueles servidores.

Por fim, no intuito de estabelecer uma adequada implantação da gestão por competências no setor público, Bastos, Borges, de Mello Neto, Sainz e de Mello (2018) identificaram a necessidade de realização de mapeamento das competências (conhecimentos, habilidades e atitudes) dos servidores da organização. Além disso, os servidores precisam estar 
sempre se atualizando (por meio de treinamento contínuo) e contar com o apoio da gestão organizacional.

Em suma, a gestão por competências nas organizações públicas federais brasileiras enfrenta desafios nos âmbitos: (i) operacionais, especialmente no que tange ao mapeamento das competências (Bastos et al., 2018; Paes et al., 2019), seleção e desenvolvimento de servidores (Cavalcante \& Renalt, 2018), fluxo de comunicação entre os departamentos (Montezano, Medeiros, Pinheiro \& de Oliveira, 2019b) e impasses burocráticos, resultando em morosidade dos processos (Fonseca \& Meneses, 2016); e (ii) estratégicos, que estão relacionados à cultura organizacional da organização em si e do serviço público em geral (Kriiger et al., 2018; Sousa \& Barbosa, 2018).

\section{Metodologia}

A abordagem desta pesquisa foi qualitativa, no intuito de compreender o fenômeno da implantação da gestão por competências em uma IES, sob a perspectiva das experiências vividas e relatadas por um grupo de trabalhadores. Segundo Flick (2013), ao analisar um fenômeno à luz da pesquisa qualitativa, o pesquisador estuda em profundidade os comportamentos dos participantes e as diferentes interações e percepções deste grupo.

Para o alcance dos objetivos desta pesquisa, optou-se pela realização de um estudo de campo, o qual busca aprofundar conhecimentos acerca de uma realidade específica, especialmente por meio do contato direto do pesquisador com a realidade a ser analisada, utilizando-se de técnicas como observação direta das atividades do grupo estudado e coleta de entrevistas (Gil, 2008). Como objeto da pesquisa de campo, julgou-se pertinente a análise da Universidade X, que possui as seguintes características: (i) é uma IES considerada uma das 20 maiores universidades do Brasil (dentre 197 instituições) no Ranking Universitário da Folha de São Paulo (RUF, 2019); (ii) é uma IES que tem buscado implantar a gestão por competências desde 2017, com a criação de um projeto piloto.

Quanto aos sujeitos da pesquisa, foram escolhidos seis servidores da Universidade X que estão vinculados à Comissão de Implantação da Gestão por Competências e a uma Pró-Reitoria Administrativa da Universidade X. Cabe esclarecer que a escolha destes sujeitos tem o intuito de observar a visão da equipe que está implantando o projeto e do grupo de gestores que vivenciarão as mudanças com a adoção da gestão por competências no órgão. Diante disso, informa-se que os seis servidores públicos entrevistados foram distribuídos em dois grupos: 
(i) Grupo 1 (servidores gestores): três servidores técnico-administrativos denominados E1, E2 e E3 (Figura 1) que atuam como gestores de uma Pró-Reitoria administrativa da Universidade X, local onde ocorrem processos de licitação, contratação de empresas e entidades de apoio, bem como gestão orçamentária e financeira de recursos.

(i) Grupo 2 (servidores da equipe de implantação): três servidores técnico-administrativos denominados E4, E5 e E6 (Figura 1) que estão lotados na Comissão de Implantação da Gestão por Competências da Universidade $\mathrm{X}$, a qual está realizando o processo de implantação da gestão por competência. Tal comissão possui 10 membros ao todo.

\begin{tabular}{|c|c|c|c|c|c|c|c|}
\hline $\begin{array}{c}\text { Entrevista- } \\
\text { do }\end{array}$ & Sexo & Idade & Escolaridade & Cargo & $\begin{array}{c}\text { Função } \\
\text { Gratificada }\end{array}$ & $\begin{array}{c}\text { Tempo na } \\
\text { Instituiçã } \\
\text { o }\end{array}$ & $\begin{array}{c}\text { Tempo } \\
\text { no } \\
\text { setor }\end{array}$ \\
\hline E1 & M & 33 & Mestrado & Administrador & $\begin{array}{c}\text { Coordenado } \\
\text { r }\end{array}$ & 4 anos & 2 anos \\
\hline E2 & F & 30 & $\begin{array}{c}\text { Especializaçã } \\
\text { o }\end{array}$ & Administrador & Assessor & 3 anos & 2 anos \\
\hline E3 & M & 38 & Mestrado & Contador & Assessor & 7 anos & 6 anos \\
\hline E4 & F & 65 & $\begin{array}{c}\text { Especializaçã } \\
\text { o }\end{array}$ & Administrador & $\begin{array}{c}\text { Coordenado } \\
\text { r }\end{array}$ & 44 anos & 4 meses \\
\hline E5 & F & 39 & Doutorado & Administrador & Não possui & 13 anos & 6 meses \\
\hline E6 & F & 35 & Mestrado & $\begin{array}{c}\text { Secretária } \\
\text { Executiva }\end{array}$ & $\begin{array}{c}\text { Diretora da } \\
\text { Divisão }\end{array}$ & 5 anos & 6 meses \\
\hline
\end{tabular}

Figura 1. Caracterização dos sujeitos da pesquisa

Fonte: Elaborado pelas autoras

A técnica de coleta de dados foi feita por meio de entrevistas semiestruturadas (Gil, 2008). O roteiro de entrevistas foi adaptado para atender à realidade dos dois grupos de entrevistados, mas ambos os roteiros foram divididos em três etapas: (i) coleta de dados pessoais e profissionais; (ii) identificação da percepção dos entrevistados acerca do seu contexto do trabalho e avaliação deles sobre a forma de lotação dos servidores na IES estudada; e (iii) identificação da percepção dos gestores acerca da relevância e dos desafios no processo de implantação da gestão por competência na Universidade X.

As entrevistas foram realizadas na Universidade $\mathrm{X}$, no ambiente de trabalho dos servidores, entre os meses de maio e junho de 2019 - ou seja, antes da promulgação do Decreto n. 9.991 (2019). As entrevistas foram gravadas com o consentimento dos participantes e totalizaram 224 minutos de gravação. Posteriormente, as entrevistas foram transcritas para a consecução das análises.

O conteúdo das entrevistas foi transcrito, e analisado, em seguida, pela análise dos núcleos de sentido (ANS). A técnica de análise de dados foi a Análise dos Núcleos do Sentido (ANS), técnica adaptada por Mendes (2007), a partir da técnica de análise de conteúdo 
categorial desenvolvida por Bardin (1977), que "consiste no desmembramento do texto em unidades, em núcleos de sentido formados a partir da investigação dos temas psicológicos sobresselentes do discurso" (Mendes, 2007, p.72).

O processo de categorização dos conteúdos coletados ocorreu em três etapas: (i) leituras das transcrições das entrevistas; (ii) recorte das ideias explícitas e implícitas (foram identificadas inicialmente 14 subtemas apreendidas no discursos entrevistados); e (iii) busca de sentidos mais amplos para articulação dos modelos subjacentes às ideias (nesta fase foram identificados 4 temas empíricos referentes aos sentidos, a saber: "seleção de pessoas"; "mapeamento das necessidades do cargo"; "cultura organizacional”, "processo de implantação da gestão por competências").

Cabe esclarecer que, para a definição dos 4 temas destacados, os 14 subtemas encontrados nos achados das entrevistas deveriam estar vinculados a assuntos encontrados na literatura. Portanto, foram encontrados 14 subtemas relacionados a categorias maiores, ou seja, à seleção de pessoas, ao mapeamento de cargos, à cultura organizacional e à implantação da gestão por competência. Ressalta-se que a análise descritiva e interpretativa das falas dos seis entrevistados, bem como a descrição do contexto da Gestão por Competências da Universidade X serão apresentados na seção a seguir.

\section{Análise e Discussão dos Resultados}

\subsection{O contexto da Gestão por Competências da Universidade X}

A Universidade X é uma IES brasileira que foi fundada nos anos de 1950. Atualmente apresenta grande número de unidades, com atividades diversificadas e um total de 3.377 servidores Técnicos Administrativos e, apesar da promulgação do Decreto n. 5.707 (2006), a implantação da Gestão por Competências teve suas atividades efetivamente iniciadas em dezembro de 2017, a partir da criação de uma Divisão, com três membros (os entrevistados E4 E5 e E6). Destaca-se que, além desta Divisão, foi criada no mesmo ano, uma Comissão de Implantação da Gestão por Competências contando com dez membros, todos servidores públicos do órgão, para o auxílio dessa atividade.

Desde 2019, o projeto piloto tem sido testado apenas em uma unidade da administração central da Universidade X, sendo acompanhada pela Pró-Reitoria de Gestão de Pessoas 
(PRGP), conforme processo de implantação do modelo de gestão por competência representado na Figura 2, abaixo.

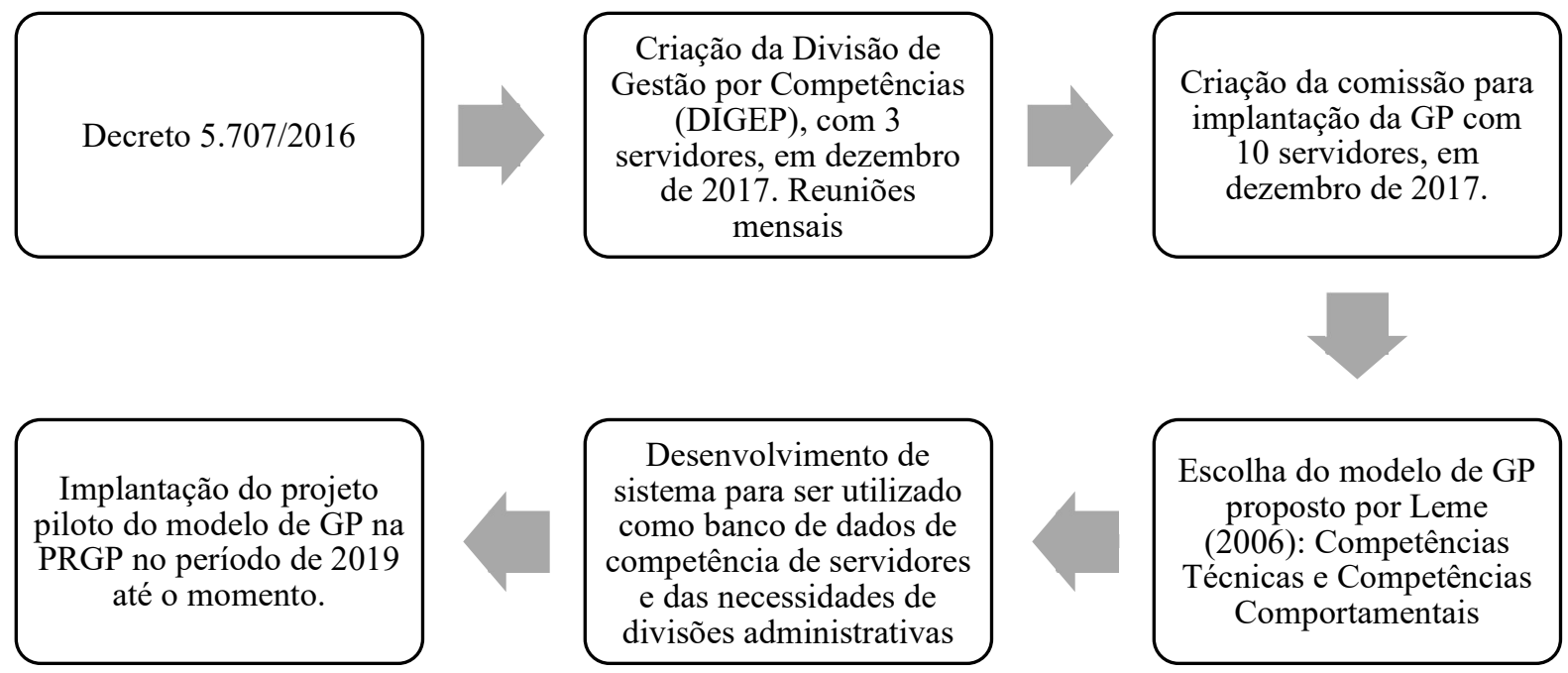

Figura 2: Processo de implantação da gestão por competências na Universidade X Fonte: Elaborado pelas autoras

De acordo com os entrevistados, a Comissão de Implantação esteve empenhada em desenvolver um sistema informatizado que possibilitará alcançar os seguintes objetivos: (i) mapear as competências necessárias para cada cargo e função das unidades administrativas da Universidade X; (ii) mapear as competências de todos os servidores da Universidade X; (iii) realizar a lotação e remanejamento dos servidores tendo como prioridade as suas competências e as competências do cargo a ser ocupado; e (iv) desenvolver as competências dos servidores por meio de ações de treinamento e outros meios de ensino.

Pelo exposto, com a implantação da gestão por competências, a Universidade X passará a identificar as necessidades do cargo e as competências dos servidores para, assim, realizar a lotação dos seus servidores, além de proporcionar treinamentos para a melhoria das funções desempenhadas.

\subsection{Grupo 1: relatos dos servidores gestores}

\subsubsection{Seleção de pessoas}

O tema empírico seleção de pessoas é composto por dois subtemas, sendo eles: indicação de gestores e lotação de servidores. Os entrevistados se referiram à indicação de servidores aos 
cargos de confiança (e, portanto, cargos de gestão) na Universidade X, mais especificamente, no seu departamento.

Acerca da indicação de gestores, E1 relata que, atualmente, a escolha dos servidores para ocupar um cargo de confiança na Universidade X é feita pela experiência do atual gestor chefe da unidade, que é o Pró-Reitor. Assim, o Pró-Reitor escolhe o servidor pela confiança naquele trabalhador e pela identificação da capacidade de liderança do mesmo. Portanto, não há recrutamento e nem seleção interna. Corroborando com o exposto, E3 afirma que a escolha de um servidor para ocupar cargo de confiança é feita pela percepção do Pró-Reitor nos aspectos que o mesmo considera como importantes, como a trajetória e experiência profissional, qualificação técnica e bom relacionamento com a sua equipe de trabalho.

Ainda sobre indicação de gestores, E1 relata que, atualmente, há a ausência de uma política de gestão de pessoas institucionalizada no órgão, quando se trata de realizar a lotação dos servidores de forma que os critérios técnicos se sobressaiam aos políticos. Como consequência disso, E1 destaca que a ausência de um projeto específico na escolha de servidores pode, a longo prazo, prejudicar os processos a serem desenvolvidos na Universidade $\mathrm{X}$, dando destaque à incapacidade de governança do órgão, como relatado no seguinte trecho: "A ausência de uma política de gestão de pessoas institucionalizada dentro do órgão, no qual os critérios técnicos se sobrepõem aos critérios políticos, ao longo prazo, ele vai minando a capacidade de governança do órgão, né" (E1).

Uma outra dificuldade destacada pelo entrevistado E3 é que, para a escolha dos gestores para cargos de confiança, além de o Pró-Reitor da unidade ter que escolher um servidor com as capacidades necessárias para o desempenho satisfatório do cargo, ele precisa convencê-lo a assumir tal responsabilidade, considerando a ausência de remuneração condizente com as atribuições a serem desempenhadas.

\footnotetext{
"Mas, por trás desse problema [indicação de gestores] também tem uma questão que, no meu ponto de vista, é uma deficiência. Você não tem uma remuneração com a atividade de gestão pra oferecer pra essas pessoas [...]eu acredito que é até uma questão de convencer, né? Não só de encontrar a pessoa correta" (E3).
}

Com relação ao subtema lotação de servidores para atuarem nas unidades da Universidade X (independentemente de o servidor atuar em cargo de gestão ou não), E3 informa que há pontos nessa forma de lotação que poderiam ser melhorados, pois os servidores são distribuídos de acordo com as necessidades burocráticas identificadas na PRGP, sem que os gestores das unidades sejam consultados acerca do perfil de competências desejado de servidores. Dessa 
forma, as competências dos servidores não são analisadas de forma mais profunda, o que obtém como resultado uma deficiência de pessoal nas unidades.

"Eu acho que é um dos pontos que possa ser melhorado [lotação de servidores] [...] não tem essa questão das competências, você necessita de gente e, às vezes, chega uma pessoa que, né.. não tem o perfil pra aquele trabalho, mas aí, quem tá lá na ponta não pode dizer, né[...] e aí você tem a deficiência de pessoal" (E3).

Em afinidade com o exposto, E1 afirma que a distribuição dos servidores é realizada de forma amadora, considerando que não há um processo de gestão de pessoas para isso, tendo em vista essa escolha que ocorre de forma aleatória, onde o gestor da unidade não é consultado e não consegue selecionar a sua equipe.

"Quando chega o servidor é aleatório [...] você não pode selecionar a sua equipe. A equipe vem de acordo com o concurso que tá vigente ou do pessoal que tá na PRGP querendo fazer redistribuição [...] Isso é feito de forma ainda amadora" (E1).

Ainda quanto ao subtema lotação de servidores, E1 destaca que os gestores que têm mais influência dentro do órgão acabam sendo beneficiados na distribuição tanto de servidores quanto ao número de funcionários terceirizados contratados para a sua unidade (terceirizados são os trabalhadores que não fizeram concurso público, mas possuem vínculo empregatício com a Universidade X baseado na Consolidação das Leis do Trabalho).

\subsubsection{Mapeamento das necessidades do cargo}

O tema empírico mapeamento é composto por dois subtemas, sendo eles: descrição dos cargos e treinamento. No que se refere descrição dos cargos, E1 relata que desconhece uma política de dimensionamento e distribuição de pessoas realizada com racionalidade. Além disso, o entrevistado afirma que nunca foi perguntado a respeito das atribuições que um novo servidor vai precisar desempenhar pra tentar encaixar com as características do setor. Além disso, o entrevistado ressalta que o servidor chega a nova unidade sem que haja uma preparação prévia.

\footnotetext{
"Não existe uma política, [...] mas se existir eu desconheço [...]. O dimensionamento e a distribuição do servidor na Universidade é totalmente nonsense. [...] Eu recebo o servidor hoje, mas não me perguntam quais são as atribuições que aquela pessoa vai desempenhar pra tentar encaixar a oferta que tem no servidor com a demanda que tem nas unidades [...] simplesmente o servidor é alocado. A PRGP dá uma cartinha pra ele se apresentar e pronto...E ai toca o barco. Nem tem uma preparação" (E1).
}

Como consequência dessa ausência de mapeamento das necessidades do cargo, bem como das competências presentes no servidor a ser lotado na unidade de trabalho, E1 destaca que unidades que necessitam de servidores mais experientes podem acabar recebendo servidores novatos e sem as experiências profissionais requeridas para aquele cargo. Corroborando com o exposto, E3 ressalta que há casos em que o servidor é lotado em uma 
unidade para desempenhar uma atividade em que ele não usa todas as suas competências e, ao mesmo tempo, uma unidade que tem atividades que necessitam de várias competências acaba não tendo um servidor disponível. Portanto, na visão do E3, a Universidade X não utiliza o servidor da forma mais adequada.

Quanto ao subtema treinamento, o entrevistado E3 informa que a PRGP realiza, anualmente, o Levantamento das Necessidades de Capacitação (LNC) de servidores, onde os próprios servidores recebem um e-mail e indicam suas próprias necessidades de treinamento. Quanto a esse levantamento, E1 destaca que esse processo feito pela PRGP ocorre sem que haja um mapeamento dentro das unidades, o que leva ao não conhecimento de quais cursos seriam realmente necessários para que o servidor consiga exercer suas atividades. Em afinidade com o exposto, E3 acredita que essa forma de levantamento seja falha, pois a indicação das necessidades de capacitação parte do próprio servidor sem que haja uma atividade coordenada para verificação das competências a ser desenvolvida pela equipe.

"O servidor recebe um e-mail que eles [PRGP] dispararam pra todos os servidores e ai o servidor indica qual é o tipo de capacitação que ele acha mais conveniente ter, né [...] acaba sendo o ponto que eu acho falho, muitas vezes depende mais da iniciativa do próprio servidor [...] não é uma atividade coordenada, né, nesse sentido de verificar que capacitações são necessárias (E3).

Além dessa forma de levantamento de capacitação realizado pela PRGP, E1 ressalta que, no momento da avaliação de desempenho dos servidores, os gestores indicam se há a necessidade de capacitação do servidor e indicam qual seria a necessidade e, então, a PRGP faz um mapeamento dessas necessidades e propõe cursos aos servidores com a demanda que se apresentou maior.

\subsubsection{Cultura organizacional}

O tema cultura organizacional apresenta um subtema, a atitude. Quanto ao subtema atitude, o entrevistado E1 acredita que a forma de escolha dos servidores por meio de critérios pessoais e a ausência de uma política de gestão de pessoas dentro da Universidade $\mathrm{X}$ acaba frustrando o servidor, o que leva ao desinteresse por capacitação, à falta de esforço no desempenho do trabalho e à fuga de recebimento de novas responsabilidades.

\footnotetext{
"Quando você elimina esse critério e deixa só pra indicação política, a pessoa se frustra, né...Não busca a capacitação, não busca ser um servidor melhor. 'Não, nunca vou chegar lá, vou ficar com o meu salário aqui pra sempre'. 'Não vou me esforçar, vou me esconder' [...], 'não me bote atribuição', etc. Então, a ausência de uma política de gestão de pessoas, a longo prazo, prejudica muito o órgão" (E1).

"Tem entrado muita gente aqui na [Universidade X] especificamente, com o perfil já diferente, mas ainda tem muita gente que busca um porto seguro no serviço público e isso vai de encontro, a pessoa não vai ter aquele ambiente, né...monótono" (E3).
} 
E3 ressalta que ainda há uma cultura dos servidores públicos na busca de estabilidade e de monotonia no trabalho, porém, o entrevistado acredita que essa cultura está mudando.

\subsubsection{Processo de implantação da gestão por competência}

O tema implantação da gestão por competência apresenta um subtema, que é benefícios à organização e benefícios aos servidores. Quanto ao subtema benefícios à organização, E2 acredita que a utilização da gestão por competências traga benefícios para a Universidade X no que se refere a maior agilidade nos processos. Na visão de E1, no entanto, o principal desafio a ser superado no que tange à implementação da gestão por competências refere-se ao desafio político, considerando que ao implantar a gestão por competências na Universidade $\mathrm{X}$, a organização estabelece critérios e eles terão que ser seguidos, o que acaba dificultando a seleção sob os interesses políticos.

\footnotetext{
"Essa ação descentralizada da Pró-Reitoria da gestão de pessoas [...] de conseguir mapear essas competências, em comum acordo com os gestores [...] colocar as pessoas nas divisões com os gestores, talvez seja o maior desafio [...]. O desafio é político. Quando você estabelece uma política de gestão por competências, você acaba prejudicando ou dificultando essa seleção política, né” (E1).
}

Em sintonia com o exposto, E3 acredita que haveria maior agilidade nos processos e, principalmente, naqueles considerados como mais complexos. O E3 acredita também que por meio do levantamento das competências, a Universidade X poderia aderir a grupos de trabalho, o que organizaria melhor o pessoal disponível para enfrentar as dificuldades da organização.

"Eu imagino que a gente teria um... um... uma agilidade maior nesses processos, né [...] se você tivesse essa questão das competências você já poderia, sei lá, criar um grupo de trabalho, o que organizaria melhor as pessoas pra poder conseguir enfrentar essas dificuldades que a gente tem" (E3).

Quanto ao subtema benefícios aos servidores, E1 destaca que a implantação da gestão por competências poderá ser uma política de longo prazo que conseguirá alcançar a meritocracia na ocupação de cargos de chefia, estimulando os servidores a buscarem se capacitar e se esforçar para conseguir pleitear cargos de gestão e buscarem melhor relacionamento entre os outros servidores. Além disso, E1 defende que a gestão por competência possibilitará melhor aproveitamento das competências dos servidores da Universidade X e a satisfação destes no desempenho de suas tarefas.

\subsection{Grupo 2: relatos dos servidores da equipe de implantação}

\subsubsection{Seleção de pessoas}


O tema empírico seleção de pessoas apresenta dois subtemas, sendo eles: indicação de gestores e lotação de servidores. No que se refere ao subtema indicação de gestores para a ocupação de cargos de confiança na unidade, E6 relata que a escolha acontece por indicação política ou mediante o critério de maior tempo na unidade, possivelmente apresentando maior experiência. No entanto, o entrevistado afirma que não há, atualmente, critério estratégico para a indicação.

\footnotetext{
“A gente percebe que é mais assim por questão de ou política, ou então é quem já está naquela função há mais tempo naquele setor há mais tempo, que talvez tenha mais experiência [...] mas assim, critério estratégico baseado coisas mais objetivas, de capacidades e competências, assim...não existe" (E6).
}

Quanto ao subtema lotação de servidores, o entrevistado E4 relata que, na primeira lotação dos servidores, o novo servidor preenche uma ficha que é analisada por uma psicóloga e, em acordo com a coordenadora, encaminha o servidor para a unidade de destino. Além disso, E4 afirma que, às vezes, o servidor é lotado em um local que ele não consegue se adaptar, mas apesar disso, ele não poderá solicitar a remoção a pedido, devendo então, se manter na unidade pelo período do estágio probatório do servidor público federal ( 3 anos).

Ainda com relação a essa forma de lotação e remoção de servidores, E4 relata que a PRGP está necessitando de um trabalho técnico de dimensionamento para a orientação na lotação, pois dessa forma, os critérios seriam definidos e não seriam facilmente modificados por outras pessoas: "A gente precisa realmente de um trabalho técnico de dimensionamento que nos oriente, né [...] sem que ninguém possa mudar aquilo que a gente decida porque a gente tem critérios [...] justificativa pra aquilo acontecer, né" (E4).

Corroborando com o exposto, E6 acredita que o órgão precisa instituir uma política de movimentação e de lotação de servidores que leve em conta o desenvolvimento, as capacidades e as habilidades do servidor para que ele consiga estar em um lugar onde ele se sinta melhor e consiga contribuir de maneira mais satisfatória: "Precisa existir, sim, uma política de movimentação e de lotação que leve em conta o desenvolvimento, as capacidades, as habilidades dos servidor [...] onde ele possa contribuir mais pra universidade" (E6).

\subsubsection{Mapeamento das necessidades do cargo}

Com referência ao tema empírico mapeamento, se obteve dois subtemas, sendo eles: treinamento e ausência de sistema integrado

Quanto ao subtema treinamento, o entrevistado E4 relata que, anualmente, a Universidade $\mathrm{X}$ realiza um levantamento das necessidades de capacitações dos servidores, onde os próprios servidores solicitam os cursos que considera importante para o seu desenvolvimento. Quanto à

Revista Gestão e Secretariado (GeSec), São Paulo, SP, 12(2), maio/ago., 2021, 173-202. 
avaliação de eficácia do curso, E5 afirma que desconhece se alguma avaliação posterior à realização de cursos de capacitação dos servidores, e em afinidade, E6 ressalta que os cursos são realizados com base em uma necessidade detectada, ocorre que não há como responder se o servidor supriu a necessidade de treinamento, tendo em vista que, posteriormente à realização do curso, o servidor não é avaliado.

"Não tem como a gente responder isso [eficácia da capacitação para a universidade]. [...] Como é que eu posso dizer que [...] supriu essa necessidade, se depois o servidor também não vai ser avaliado em cima dessa necessidade que foi detectada?" (E6).

Quanto ao subtema ausência de sistema integrado para o mapeamento das necessidades de capacitação dos servidores, E6 destaca que ainda não existe um sistema ou uma metodologia que consiga identificar tais necessidades, não existindo, atualmente, uma integração das necessidades indicadas pelas chefias quanto pelos servidores.

"Não existe um sistema integrado. Em que sentido? De que eu identifico as necessidades de capacitação dos servidores. Muitas vezes não é pelo que meu chefe me diz, ou por uma necessidade que foi detectada no meu setor por meio de uma avaliação" (E6).

O entrevistado E6 ainda ressalta que há servidores capacitados, porém eles não têm oportunidade de desempenhar seu trabalho utilizando todo o seu potencial em termos de competências.

\subsubsection{Processo de implantação da gestão por competência}

O tema processo de implantação da gestão por competências apresentou três subtemas, sendo eles: fundamentação legal, funcionamento, cultura organizacional.

Quanto ao subtema fundamentação legal, E6 relembra que, no ano de 2006, por meio do Decreto n. 5.707 (2006), foi instituída a política de gestão por competências nos órgãos vinculados à esfera pública. E4 esclareceu que o governo federal está exigindo dos órgãos públicos maior profissionalização das suas atividades. Nesse contexto, entretanto, E5 informa que existem dificuldades em realizar a implantação no órgão, tendo em vista que não é algo pronto para ser implantado.

Quanto aos objetivos, E6 declara que a gestão por competências é uma ferramenta que busca integrar todos os processos para desenvolver as habilidades, competências técnicas, e competências comportamentais dos servidores. Ademais, E4 informou a existência de uma comissão para a implantação da gestão por competências, composta por 10 pessoas, com reuniões mensais. 
No que diz respeito ao subtema funcionamento, o entrevistado E5 relata que a comissão está implantando a gestão por competências na instituição juntamente com a Administração Superior da PRGP e, juntamente com ela, houve a definição dos gestores que iriam participar do projeto piloto da implantação da gestão por competências na Universidade X. E5 destaca que os gestores escolhidos representam a amostra da PRGP para participar do projeto piloto, o qual está na primeira etapa de mapeamento.

E6 informa que a equipe de implantação está mapeando as competências dos servidores por meio dos componentes de competências comportamentais, colhido por meio do inventário comportamental, e por meio das competências técnicas, coletadas mediante o inventários das responsabilidades, como relatado no seguinte trecho: "A gente fez dois tipos de mapeamento: mapeamento das competências comportamentais, por meio do inventário comportamental, e o mapeamento das competências técnicas, por meio do inventário das responsabilidades" (E6).

Ademais, E5 informa que modelo gestão por competências proposto por Leme (2006) é construtivo e mais adequado à realidade da Universidade $\mathrm{X}$, tendo como parâmetros teóricos os conceitos de competência técnicas e comportamentais. No entanto, E4 afirma que a implantação do modelo de gestão por competências ainda não foi divulgada para as demais unidades da Universidade X.

No que tange à temática cultura organizacional, o entrevistado E5 acredita que o grande desafio para a implantação da gestão por competências refere-se a estrutura rígida do órgão, bem como pela necessidade de mudança cultural dos servidores. Em afinidade com o exposto E4 relata que, pela experiência que possui no órgão, um dos grandes entraves refere-se à cultura, ou seja, há a necessidade de mudança da cultura organizacional. Além do exposto, E5 afirma que o grande desafio para o sucesso da implantação da gestão por competências é conseguir desenvolver o próprio sistema. E4 destaca que a estabilidade dos servidores é algo nocivo tanto para a instituição quanto para o servidor, pois, apesar do servidor entrar na IES motivado para o desempenho das atividades, ele percebe a cultura organizacional e, dessa forma, ela acaba se contaminando.

\footnotetext{
"Essa coisa da estabilidade é uma coisa ruim pra instituição e é ruim para o servidor também porque quando você não tem o que buscar, você também se acomoda, certo? Termina que a pessoa quando chega na Universidade, ela vem com vontade de fazer coisas, mas depois ela começa a ver que é tudo muito difícil [...] aí aquela coisa vai contaminando, certo?" (E4).
}

Em complemento, E4 acredita que a implantação da gestão por competências na Universidade X vai buscar conectar a capacitação, a avaliação, a movimentação e, no futuro, até o concurso público. Além disso, E4 ressalta que muitos dos componentes de gestão por 
competências já são utilizados na Universidade X, porém, ocorrendo de forma desconectada. Nesse sentido, E6 afirma que a gestão por competências vai valorizar o servidor, bem como realizar a gestão de pessoas de uma forma integrada. Além disso, E6 acredita que, quando o servidor se sente valorizado, a Universidade $\mathrm{X}$ vai chegar nos seus objetivos mais facilmente.

\section{Discussão e síntese dos resultados}

Apesar de ocuparem posições diferenciadas no processo de implantação da gestão por competências na Universidade $\mathrm{X}$, os participantes das entrevistas evocaram núcleos de significado semelhantes, a saber: seleção de pessoas, mapeamento das necessidades do cargo, e processo de implantação da gestão por competências. A partir das visões complementares dos dois grupos entrevistados, foi possível identificar os desafios enfrentados na implementação e desenvolvimento do processo da gestão por competências na Universidade $\mathrm{X}$ e, consequentemente, inferir as perspectivas relacionadas à gestão por competências na organização em estudo.

Notou-se que, embora a ideia de competências para os participantes da pesquisa tenha se aproximado da tríplice conceitual "conhecimentos-habilidades-atitudes" (Durand, 1998; Le Boterf, 2003), identificou-se a predominância da perspectiva dual "competências técnicas versus competências comportamentais" (Leme, 2006) no discurso dos participantes. Este posicionamento ficou diluído nas falas dos entrevistados em diferentes momentos, especialmente quando demonstraram que a gestão por competências deve levar em consideração questões atitudinais (relativos à pré-disposição dos servidores a cooperar com a gestão e a buscar o desenvolvimento de suas competências) e comportamentais (relacionados à prática dos servidores no exercício do seu trabalho, desenvolvendo suas capacidades técnicas e gerenciais, bem como as suas soft skills).

A gestão por competências tem sido utilizada em um projeto piloto enquanto uma ferramenta organizacional para levantar as necessidades dos trabalhadores nos seus devidos cargos e funções (Leme, 2005). No entanto, os servidores entrevistados na Universidade X relataram algumas situações que podem ser interpretadas como os gargalos da implementação da gestão por competências na instituição, características sobre as quais é possível inferir nas razões que levaram à lentidão no pleno processo de desenvolvimento desse modelo de gestão. Essa situação se assemelha ao estudo empírico de Fonseca e Menezes (2016), que concluíram que a gestão por competências se encontra em um estágio ainda inicial nas organizações públicas que eles investigaram. 
Quanto à temática de seleção de pessoas, ficou claro que a indicação de gestores para cargos de confiança e a de lotação de servidores para as unidades administrativas não estão padronizadas de acordo com os parâmetros da gestão por competências. Isto porque, de acordo com Leme (2005), seleção de trabalhadores por competências busca identificar os candidatos com as características comportamentais adequadas para cada cargo ou função, no intuito de alocar de maneira mais eficiente os trabalhadores. No entanto, na Universidade X, as indicações e questões políticas da organização prevalecem nos processos de seleção.

O relato dos entrevistados acerca do mapeamento das necessidades do cargo, por sua vez, foi coerente com Bastos et al., (2018), no sentido de que há uma necessidade de mapear as competências dos servidores. Este esforço busca garantir para a Universidade X o pleno desenvolvimento de todo o processo de implantação da gestão por competência da organização, caso contrário, esse processo será prejudicado (Brantes, 2012).

Nesse contexto, a pesquisa revelou a problemática da gestão da Universidade $\mathrm{X}$ em se comunicar internamente (entre a PRPG e a unidade), tanto para melhor descrever as competências necessárias para que um novo servidor ocupe certo cargo, como para identificar as reais necessidades de treinamentos que catalisam as competências dos servidores. No entanto, ressalta-se que o ideal é identificar os trabalhadores mais competências para certos os cargos, pois nem sempre uma pessoa dedicada é a mais qualificada a desenvolver certas atividades, tornando problemático o alcance do trabalho de forma mais produtiva (Ferreira \& Soeira, 2013; Sovienski \& Stigar, 2008).

Ressalta-se que, os gestores entrevistados mencionaram a questão da comunicação deficiente entre os departamentos (unidade administrativa e PRPG), dificultando a implementação de treinamentos adequados e de alocação de servidores em cargos onde são exigidas competências específicas. Este resultado corrobora com o que versam Montezano et al., (2019b), uma vez que esses autores identificaram uma nova modalidade de desafios que interferem na implementação da gestão por competências, que é a comunicação.

No que tange à cultura organizacional, os entrevistados relataram que alguns servidores, ao serem lotados aleatoriamente no seu cargo, adotam um comportamento desinteressado, sem buscar o desenvolvimento de suas competências, pois estão focados na estabilidade e monotonia do serviço público. Nesse sentido, há uma necessidade de sensibilização dos servidores para a emergência da gestão por competências, como relatado no estudo empírico de Kriiger et al., (2018). bem como explicado por (Gramigna, 2007), o qual alerta aos atores organizacionais a necessidade de constante sensibilização no intuito de desenvolver o comprometimento e a motivação das equipes de trabalho. 
Ademais, os conteúdos evocados pelos entrevistados sobre a necessidade de uma mudança na cultura organizacional estão de acordo com o que versam Silva e Mello (2013), os quais enfatizam que, a implementação da gestão por competências exige da organização a busca adaptar-se às mudanças, sejam elas estruturais ou referentes ao campo estratégico, como cultura organizacional, missão e valores. destacam que o grande desafio consiste em realizar a mudança de um modelo burocrático para um modelo gerencial de resultados, onde se faz necessária a alteração da cultura organizacional do serviço público, sendo necessário o comprometimento e ação dos envolvidos, bem como o alinhamento do mesmo à estratégia da instituição. Silva e Mello (2013)

No que diz respeito ao processo de implantação da gestão por competências, os maiores desafios giram em torno de questões burocráticas e de resistências por parte dos servidores no cumprimento de novas normas, concordando com os resultados de Cavalcante e Renalt (2018), os quais ressaltam a necessidade de melhoramentos quanto a estruturação e execução do próprio modelo de gestão por competências, incluindo a superação de questões burocráticas da instituição.

Por fim, a Figura 5 apresenta a síntese dos resultados deste estudo, considerando os núcleos do sentido, os desafios enfrentados pela Universidade X (na percepção dos entrevistados) e as perspectivas, ou seja, as prospecções de possíveis resoluções e melhorias frente às dificuldades enfrentadas (inferidas como resultantes das análises das entrevistas realizadas).

\begin{tabular}{|c|c|c|}
\hline $\begin{array}{l}\text { Núcleos do } \\
\text { sentido }\end{array}$ & Desafios & Perspectivas \\
\hline $\begin{array}{c}\text { Seleção de } \\
\text { pessoas }\end{array}$ & $\begin{array}{l}\text { *Critérios subjetivos na indicação e lotação } \\
\text { de servidores e terceirizados para cargos de } \\
\text { gestão; } \\
\text { *Ausência de remuneração extra para o } \\
\text { servidor que assume cargos gerenciais de } \\
\text { confiança, mesmo diante do aumento de } \\
\text { responsabilidades; } \\
\text { *Critérios políticos muitas vezes superam os } \\
\text { critérios técnicos na indicação de servidores } \\
\text { para assumir cargos gerenciais de confiança. }\end{array}$ & $\begin{array}{l}\text { *Há uma expectativa de que o Governo } \\
\text { Federal regule maneiras mais objetivas de } \\
\text { seleção de pessoas para atuarem nas unidades } \\
\text { administrativas da organização, de forma a } \\
\text { melhor orientar os pró-reitores na sua tomada } \\
\text { de decisão quanto aos processos internos } \\
\text { relacionados principalmente à lotação de } \\
\text { novos servidores e à indicação de servidores } \\
\text { para assumir cargos gerenciais de confiança, } \\
\text { levando-se em consideração as competências } \\
\text { necessárias para o provimento do cargo vago. }\end{array}$ \\
\hline $\begin{array}{l}\text { Mapeamento } \\
\quad \text { das } \\
\text { necessidades } \\
\text { do cargo }\end{array}$ & $\begin{array}{l}\text { *A comunicação deficiente entre os } \\
\text { departamentos dificulta tanto a } \\
\text { implementação de treinamentos adequados, } \\
\text { como a alocação de servidores em cargos }\end{array}$ & $\begin{array}{l}\text { *A integração da comunicação entre a PRGP } \\
\text { e as unidades da Universidade X se torna } \\
\text { essencial, uma vez que o provimento dos } \\
\text { cargos não deve atender apenas às demandas }\end{array}$ \\
\hline
\end{tabular}




\begin{tabular}{|c|c|c|}
\hline & $\begin{array}{l}\text { onde são exigidas competências específicas, } \\
\text { as quais, muitas vezes, o servidor não possui. }\end{array}$ & $\begin{array}{l}\text { burocráticas, mas deve-se colocar em } \\
\text { evidência as competências necessárias para } \\
\text { que o servidor assuma certo cargo na } \\
\text { Universidade X e o devido treinamento } \\
\text { oferecido a ele, gerando benefícios para } \\
\text { ambos (trabalhador e organização). }\end{array}$ \\
\hline $\begin{array}{c}\text { Cultura } \\
\text { organizacional }\end{array}$ & $\begin{array}{l}\text { * Manter os servidores motivados torna-se } \\
\text { um desafio no contexto de cultura } \\
\text { organizacional equivocadamente } \\
\text { disseminada sobre a monotonia do serviço } \\
\text { público, incentivando alguns servidores a } \\
\text { serem resistentes quando ao } \\
\text { desenvolvimento de suas competências. }\end{array}$ & $\begin{array}{l}\text { *Espera-se da Universidade X a implantação } \\
\text { e disseminação de um modelo de gestão de } \\
\text { pessoas que esteja atendo aos aspectos } \\
\text { motivacionais dos servidores e, ao mesmo } \\
\text { tempo, priorize o desenvolvimento de suas } \\
\text { competências. }\end{array}$ \\
\hline $\begin{array}{l}\text { Processo de } \\
\text { implantação da } \\
\text { gestão por } \\
\text { competências }\end{array}$ & $\begin{array}{l}\text { *Por ser um processo complexo, a } \\
\text { implantação da gestão por competência } \\
\text { enfrenta desafios como: questões } \\
\text { burocráticas e resistência de servidores no } \\
\text { cumprimento de novas normas. }\end{array}$ & $\begin{array}{l}\text { *Acredita-se que o processo de implantação } \\
\text { da gestão por competências está ancorado nos } \\
\text { elementos da cultura organizacional da } \\
\text { Universidade X e, portanto, a plena } \\
\text { implantação desse modelo de gestão está } \\
\text { intimamente associada à implementação de } \\
\text { práticas gerenciais inovadoras onde as } \\
\text { competências de gestores e demais servidores } \\
\text { sejam enaltecidas. }\end{array}$ \\
\hline
\end{tabular}

Figura 3. Síntese dos resultados

Fonte: Elaborado pelas autoras

A seguir serão apresentadas as considerações finais, que contêm as principais contribuições da pesquisa, bem como as limitações e as sugestões para pesquisas futuras.

\section{Considerações Finais}

Este trabalho teve como objetivo compreender os desafios e as perspectivas no processo de implantação da gestão por competências em uma IES. Inicialmente, cumpre destacar que a complexidade do modelo de gestão por competências foi uma característica que sobressaiu na fala dos entrevistados, considerando que não é um modelo pronto a ser implantado, ou seja, necessita ser construído junto às demais unidades da Universidade $\mathrm{X}$.

A partir dos núcleos do sentido captados nas entrevistas semiestruturadas, foi possível identificar diferentes desafios no processo de implantação da gestão por competências na Universidade X. Assim, identificou-se que apesar de a legislação obrigar a adoção da gestão por competências desde 2006, a instituição ainda não obteve êxito em atendê-la plenamente em 
decorrência do ambiente complexo; da necessidade de mudança na cultura organizacional referente aos costumes políticos; da rigidez em sua estrutura; da necessidade de motivar servidores a se capacitarem, apesar da estabilidade da função adquirida por meio da legislação vigente, ainda não se obteve sucesso em sua efetiva implantação.

Em seguida, foram identificadas as perspectivas, ou seja, as prospecções de possíveis resoluções e melhorias frente aos desafios enfrentados pelos servidores. Assim, identificou-se como principais perspectivas: a regulamentação de maneiras mais objetivas de seleção de pessoas, levando-se em consideração as competências necessárias para o provimento do cargo vago; o mapeamento dos das competências de forma a alocar os servidores de acordo com as com as competências necessárias para o cargo, e não apenas para atender apenas às demandas burocrática; e a disseminação da gestão por competências como uma prioridade na cultura organizacional.

Cabe destacar que as entrevistas semiestruturadas foram realizadas na Universidade X, entre os meses de maio e junho de 2019, e que, atualmente, o Decreto n. 5.707 (2006) foi revogado e, em seu lugar, foi promulgado o Decreto n. 9.991 (2019) - que também dispõe sobre a Política Nacional de Desenvolvimento de Pessoal (PNDP) e tem como intuito a promoção do desenvolvimento dos servidores públicos nas competências necessárias à consecução da excelência na atuação dos órgãos e das entidades da administração pública federal direta, autárquica e fundacional. Nesse sentido, verifica-se que, apesar dos 13 anos de vigência do Decreto n. 5.707 (2006), a Universidade X não conseguiu implantar efetivamente a Gestão por Competência no órgão, estando, ainda, em etapa de implantação de projeto piloto em apenas uma unidade administrativa do órgão e, a partir da vigência do Decreto n. 9.991 (2019), a Universidade $\mathrm{X}$ ainda terá que adaptar a implantação da gestão por competências às alterações trazidas pelo novo Decreto supracitado.

Apesar de este estudo não ter o objetivo de generalização dos resultados para todas as organizações públicas do âmbito federal, acredita-se que as perspectivas, assim como os desafios supracitados, contribuam para o aprimoramento das atuais demandas requeridas ao serviço público federal e, mais especificamente, para a orientação de outras universidades públicas federais que estejam em fase inicial de implantação desse modelo de gestão de pessoas, auxiliando na prática de gestores públicos na fase de implementação e de manutenção da gestão por competências. Este artigo esclareceu e confirmou os desafios enfrentados pela Universidade $\mathrm{X}$ no seu processo de implementação da gestão por competências e que, possivelmente, são semelhantes aos que enfrentam outras universidades do âmbito federal em fase inicial de implantação desse modelo de gestão de pessoas.

Revista Gestão e Secretariado (GeSec), São Paulo, SP, 12(2), maio/ago., 2021, 173-202. 
Ressalta-se a possibilidade de realizar, como estudo posterior, a análise da gestão por competências em uma Instituição Pública de Ensino Superior que tenha conseguido, de forma satisfatória, a superação dos desafios relatados na implantação da gestão por competências como forma de gestão de pessoas no órgão, conforme determinado pelo Decreto $\mathrm{n}^{\mathrm{o}} 5.707$ (2006), atualmente revogado, mas atualizado pelo Decreto n. 9.991 (2019), como também pela promulgação Decreto n. 9.727 (2019) que dispõem sobre critérios a serem observados para a ocupação dos cargos em comissão do Grupo-Direção e Assessoramento Superiores - DAS e das Funções Comissionadas do Poder Executivo - FCPE, no âmbito federal. Outra possibilidade de estudo refere-se ao retorno à Universidade X para compreensão das alterações trazidas pelos Decretos supracitados e para avaliação dos retornos obtidos após a implantação da gestão por competências no órgão, tanto no âmbito individual quanto no estratégico.

\section{Referências}

Alles, M. A. (2006). Selección por competencias. Buenos Aires: Granica.

Bardin, L. (1977). Análise de conteúdo (7a ed.). Lisboa.

Bastos, F. C. C., Borges, F., de Mello Neto, A. W., Sainz, A. B., \& de Mello, L. H. W. (2019). Gestão por competência: uma análise das competências sob a perspectiva dos servidores do IBAMA de Santa Catarina. NAVUS-Revista de Gestão e Tecnologia, 9(1), 74-86.

Brandão, H. P., \& Guimarães, T. D. A. (2001). Gestão de competências e gestão de desempenho: tecnologias distintas ou instrumentos de um mesmo construto? Revista de Administração de empresas, 41(1), 8-15.

Brandão, H. P., \& Bahry, C. P. (2005). Gestão por competências: métodos e técnicas para mapeamento de competências. Revista do Serviço Público, 56(2), 179-194.

Brantes, C. A. A. (2012). Competências e desenvolvimento de pessoas no setor público: mudanças após o Decreto 5707/2006. (Dissertação de Mestrado). Universidade Federal da Bahia, Salvador, Brasil.

Campion, M. A., Fink, A. A., Ruggeberg, B. J., Carr, L., Phillips, G. M., \& Odman, R. B. (2011). Doing competencies well: Best practices in competency modeling. Personnel psychology, 64(1), 225-262.

Carmo, L. O. (2016). Gestão de Pessoas Baseada em Competências: Um Modelo Avançado de Gestão. Revista de Administração Geral, 1(2), 101-117. 
Carvalho, A. I. D., Vieira, A. S., Bruno, F., Motta, J. I. J., Baroni, M., Macdowell, M. C., ... \& Côrtes, S. D. C. (2009). Escolas de governo e gestão por competências: mesa-redonda de pesquisa-ação. Brasília: ENAP.

Cavalcante, F. V., \& Renault, T. B. (2018). Gestão por competências: uma avaliação das práticas de gestão de pessoas em uma instituição pública de ciência e tecnologia em saúde. RAHIS-Revista de Administração Hospitalar e Inovação em Saúde, 15(2), 89-107.

Clausen, T. S., Jones, K. T., \& Rich, J. S. (2008). Appraising employee performance evaluation systems. CPA journal, 78(2), 64.

Dadoy, M. (2004). As noções de competência e competências à luz das transformações na gestão da mão-de-obra. In A. Tomasi (Org.). Da qualificação à competência. Campinas: Papirus.

Decreto n. 5.707, de 23 de fevereiro de 2006. (2006). Institui a Política e as Diretrizes para o Desenvolvimento de Pessoal da administração pública federal direta, autárquica e fundacional, e regulamenta dispositivos da Lei n. 8.112, de 11 de dezembro de 1990. Brasília, DF. Recuperado de http://www.planalto.gov.br/ccivil_03/_Ato20042006/2006/Decreto/D5707.htm

Decreto n. 5.824, de 29 de junho de 2006. (2006). Estabelece os procedimentos para a concessão do Incentivo à Qualificação e para a efetivação do enquadramento por nível de capacitação dos servidores integrantes do Plano de Carreira dos Cargos Técnico-Administrativos em Educação, instituído pela Lei no 11.091, de 12 de janeiro de 2005. Brasília, DF. Recuperado de http://www.planalto.gov.br/ccivil_03/_Ato20042006/2006/Decreto/D5824.htm

Decreto n. 5.825, de 29 de junho de 2006. (2006).

Estabelece as diretrizes para elaboração do Plano de Desenvolvimento dos Integrantes do Plano de Carreira dos Cargos Técnico-Administrativos em Educação, instituído pela Lei no 11.091, de 12 de janeiro de 2005. Brasília, DF. Recuperado de http://www.planalto.gov.br/ccivil_03/_ato2004-2006/2006/decreto/d5825.htm.

Decreto n. 9.727 de 15 de março de 2019. (2019). Dispõe sobre os critérios, o perfil profissional e os procedimentos gerais a serem observados para a ocupação dos cargos em comissão do Grupo-Direção e Assessoramento Superiores - DAS e das Funções Comissionadas do Poder Executivo - FCPE. Brasília, DF. Recuperado de http://www.planalto.gov.br/ccivil_03/_ato2019-2022/2019/decreto/D9727.htm

Decreto n. 9.991 de 28 de agosto de 2019. (2019). Dispõe sobre a Política Nacional de Desenvolvimento de Pessoas da administração pública federal direta, autárquica e Revista Gestão e Secretariado (GeSec), São Paulo, SP, 12(2), maio/ago., 2021, 173-202. 
fundacional, e regulamenta dispositivos da Lei $\mathrm{n}^{\circ}$ 8.112, de 11 de dezembro de 1990, quanto a licenças e afastamentos para ações de desenvolvimento. Brasília, DF. Recuperado de http://www.planalto.gov.br/ccivil_03/_ato2019-2022/2019/decreto/D9991.htm

Dias, C. A., Demo, G., Paula, P. P., \& Costa, A. C. R. (2020). Gestão por competências: dezoito anos de estudos no brasil. Revista PRETEXTO, 18-18.

Durand, T. (1998). Forms of incompetence. In: Fourth International Conference on Competence-Based Management. Proceedings... Oslo: Norwegian School of Management.

Dutra, J. S. (2004). Competências: conceitos e instrumentos para a gestão de pessoas na empresa moderna. São Paulo: Atlas.

Dutra, J. S., Fleury, M. T. L., \& Ruas, R. (2008). Competências: conceito, método e experiências. In Competências: conceito, método e experiências, 303-303.

Ferreira, S. F., \& Soeira, F. D. S. (2013). A importância do recrutamento e seleção de pessoas em uma empresa de pequeno porte do setor de móveis. Revista Eletrônica Diálogos Acadêmicos, 4(1), 46-56.

Flick, U. (2013). Uma introdução à metodologia de pesquisa: um guia para iniciantes. Porto Alegre: Editora Penso.

Fonseca, D. R., \& Meneses, P. P. M. (2016). Fatores para implantação e desenvolvimento da gestão por competências em agências reguladoras federais. Revista Eletrônica Científica da UERGS, 2(2), 117-133.

Gil, A. C. (2008). Métodos e técnicas de pesquisa social (6a ed.). São Paulo: Atlas.

Giudice, R. C. (2012). Desafios da gestão de pessoas por competências na Administração Pública Federal Brasileira. Revista brasileira de planejamento e orçamento, 2(2), 188-204. Gramigna, M. R. (2007). Modelo de competência e gestão de talentos. (2a ed.). São Paulo:

Pearson Prentice Hall.

Kriiger, C. C. P., de Andrade, E. P., da Silva, A. M., de Oliveira Mourão, C., Pizzol, R. A., \& Lima, S. T. P. (2018). Desafios à implantação de modelos de gestão por competências no setor público federal: o caso de uma autarquia federal. Revista do Serviço Público, 69(3), 707-740.

Le Boterf, G. (2003). Desenvolvendo a competência dos profissionais. Porto Alegre: Artmed Editora.

Leme, R. (2005). Aplicação prática de gestão de pessoas por competências: mapeamento, treinamento, seleção, avaliação e mensuração de resultados de treinamento. Rio de Janeiro: Qualitymark. 
Leme, R. (2006). Avaliação de desempenho com foco em competência. Rio de Janeiro: Qualitymark.

Mendes, A. M. (2007). Pesquisa em Psicodinâmica: a clínica do trabalho. In Mendes, A.M. Psicodinâmica do trabalho: teoria, método e pesquisas. São Paulo: Casa do Psicólogo, 6586.

Milliman, J., Nason, S., Zhu, C., \& De Cieri, H. (2002). An exploratory assessment of the purposes of performance appraisals in North and Central America and the Pacific Rim. Human Resource Management: Published in Cooperation with the School of Business Administration, The University of Michigan and in alliance with the Society of Human Resources Management, 41(1), 87-102.

Montezano, L., Medeiros, B. N., Isidro-filho, A., \& Petry, I. S. (2019a). Panorama da Produção Científica da Gestão por Competências na Administração Pública Brasileira (2008 a 2018). Contabilidade, Gestão e Governança, 22(2), 280-298.

Montezano, L., Medeiros, B. N., Pinheiro, A. O., \& de Oliveira, C. A. A. M. (2019b). Percepção de servidores de uma organização pública federal quanto à implantação da gestão por competências. Gestão e Sociedade, 13(34).

Paes, R. V. O., de Souza Figueiredo, M., de Lemos, J. F. N., \& Oliveira, M. A. (2019). Panorama da atuação do profissional de secretariado executivo na Universidade Federal do Pará através da gestão por competências. Revista de Gestão e Secretariado, 10(3), 163191.

Paiva, K. C. M., \& Melo, M. C. O. L. (2008). Competência, gestão de competência e profissões: Perspectivas de pesquisa. Rev. Adm. Contemporânea, Curitiba, 12(2), 339-368.

Pires, A. K., Prata, C. F., Santos, D. M. dos, Brandão, H. P., Moraes, H., Carvalho, I. M. de, Monteiro, J. C., Dias, J. C., E. Filho, J. V., Oliveira, M. M. S., Marques, M. I. C., Amaral, P. A., Araújo, P. B. da C., Hashimoto, R., Machado, S. S., \& Dantas, V. C. (2005). Gestão por competências em organizações de governo. Brasília: ENAP.

Rocha, G. B., Passador, C. S., \& Shinyashiki, G. T. (2017). What is the social gain from competency management? The employees' perception at a brazilian public university. RAUSP Management Journal, 52(3), 233-245.

Ranking Universitário Folha. (2019). Ranking de universidades. Recuperado de https://ruf.folha.uol.com.br/2019/ranking-de-universidades/principal/

Sansur, A. M, (2007). Gestão por competências: a percepção de ganho social do trabalhador. (Tese de Doutorado). Universidade de São Paulo, São Paulo, Brasil. 
Silva, F. M., \& Mello, S. P. T. (2013). A implantação da gestão por competências: práticas e resistências no setor público. Revista Eletrônica de Administração e Turismo-ReAT, 2(1), 110-127.

Siqueira, W. M., \& do Nascimento, D. C. (2016). Gestão por competências: desafios encontrados por uma instituição pública de Petrolina durante o processo de implementação. ID On Line Revista de Psicologia, 10(31), 43-62.

Sousa, M. G. T., \& Barbosa, M. D. F. N. (2018). A aplicação da gestão por competências nos processos de gestão de pessoas: um estudo com os servidores técnico-administrativos no centro de ciências jurídicas e sociais/UFCG. Revista de Administração Contabilidade e Sustentabilidade, 8(3), 31-46.

Sovienski, F., \& Stigar, R. (2008). Recursos humanos x gestão de pessoas. Revista científica de Administração, 10(10), 51-61.

Trasatti, S. R., \& Costa, M. I. (2010). Administração de recursos humanos por competências: a gestão do novo contrato entre pessoas e empresas do terceiro milênio. (4a ed.). In: Neri, A., et. al. Gestão de RH por competências e a empregabilidade. Campinas: Papirus.

United Nations Educational, Scientific and Cultural Organization. (2009). 2009 world conference on higher education: the new dynamics of higher education and research for societal change and development. Paris: Unesco. Recuperado de https://unesdoc.unesco.org/ark:/48223/pf0000183277

Zarifian, P. (2001). Objetivo competência: por uma nova lógica. São Paulo: Atlas.

Submetido em: 04.11.2020

Aceito em: 10.03.2021 